\title{
Vera, un cuento cruel (1973) Josefina Molina. El cine de terror visto por una directora
}

\section{Vera, un cuento cruel (1973) Josefina Molina. A Horror Spanish Movie Directed by a Woman}

\author{
Luis Deltell Escolar \\ Universidad Complutense de Madrid, España \\ ldeltell@ucm.es \\ Andrea Muñoz Giner \\ Universidad Complutense de Madrid, España \\ andreaginer@gmail.com
}

\section{Resumen:}

Se trata de un análisis de dos productos audiovisuales, ambos dirigidos por una mujer, Josefina Molina: Vera (1971) y Vera, un cuento cruel (1973). El primero de ellos es un capítulo de la serie de TVE2 la "Hora Once" y el segundo es un largometraje cinematográfico de ficción de la productora Etnos Films. Los dos textos han sido co-escritos por Josefina Molina. Estas dos producciones audiovisuales se basan libremente en el cuento "Vera" de Villiers de L'Isle-Adam.

Vera, un cuento cruel es la única película de ficción española de cine de terror del tardofranquismo dirigida y escrita por mujeres. Supone la única aportación realizada por mujeres al género de lo fantástico y del terror en su momento de esplendor en España. Su análisis resulta realmente significativo para entender el cine español de esa época marcado por una fuerte misoginia tanto en el sistema de producción como en la temática de las obras.

\begin{abstract}
:
This article analyses two Spanish audiovisual productions directed by Josefina Molina: Vera (1971) and Vera, un cuento cruel (1973). Vera was released as an episode part of the TVE2 series "Hora Once". Vera, un cuento cruel is a featurelength fiction film produced by Etnos Films. The two films were directed and written by Josefina Molina based on a short story by Villiers de L' Isle-Adam titled Vera. Vera, un cuento cruel is the only Spanish horror movie directed and written by a woman during the last few years of Franco's dictatorship, a moment in Spanish history when the horror and fantasy genre was at its most prolific. These films analysis is key in understanding how strongly misogyny influenced Spanish cinema and the fantasy genre in particular. This was undeniably tangible in all stages of film production and transpired through the themes and stories themselves.
\end{abstract}

Palabras clave: Cine de terror; fantástico; cine español; Josefina Molina; Lola Salvador; feminismo.

Keywords: Horror; Fantasic; Spanish Cinema; Josefina Molina; Lola Salvador; Feminism. 


\section{Introducción y antecedentes ${ }^{*}$}

Los géneros cinematográficos nunca cuajaron de forma significativa en España, si bien unos pocos cineastas y productores intentaron crear empresas enfocadas en algún género concreto (Medina, 2000), la inmensa mayoría de las películas se trataban de obras sin un género determinado. Como bien observa Emilio C. García Fernández (2010) el cine español se caracteriza por la mezcolanza de géneros.

Solo existe una excepción a este planteamiento: el ciclo temático del cine de terror y fantástico que se desarrolló fuertemente desde finales de los años sesenta hasta principios de los años setenta. El género fantástico español es una de las rarezas de esta industria cinematográfica por el volumen de títulos, por sus métodos de producción seriados, por su particular propuesta fotográfica y visual, por los cauces utilizados en su distribución y exhibición e, incluso, por su audaz propuesta internacional (García Fernández \& Cordero Domínguez, 2017). Entre 1965-1975 se produjeron más de 115 obras fantásticas que llegaron a representar en algunas de las temporadas casi la cuarta parte de la producción anual de largometrajes en España (Múñoz Giner, 2011). Durante esos diez años, el género fantástico español vendía anualmente más de ocho millones de entradas. Incluso algunos de sus títulos, como La residencia (Narciso Ibáñez Serrador, 1969), triunfaron internacionalmente (Cordero Domínguez, 2015).

El género fantástico se escribía y se dirigía exclusivamente por hombres que escribieron la práctica totalidad de los guiones de este ciclo (Riambau y Torreiro, 1998). Ellos configuraron una imagen cinematográfica del terror en España. Esta construcción absolutamente masculina podría permitir un análisis como el propuesto por Lesage (1974) y Laura Mulvey (1999) para el cine clásico de Hollywood y de hecho autoras españolas como Pilar Pedraza (1971 y 2004) y Begoña Siles (2006) ya señalan este ciclo temático español como uno de los más machistas y en los cuales la visión patriarcal es más dominante.

\footnotetext{
* Este artículo se enmarca dentro de la investigación de ESCINE, grupo de investigación competitivo complutense de estudios cinematográficos.
} 
Sin embargo, esta investigación se basa en la única producción que rompe esta norma; de la vasta producción solo un largometraje está firmado y escrito por mujeres: Vera, un cuento cruel (1973) que está realizado por una directora, Josefina Molina, y además está coescrito por otra: Salvador Maldonado - seudónimo de Lola Salvador Maldonado-. Por tanto, es la única obra -en este período estudiado- redactada por mujeres dentro del género de terror y, a la vez, la única que fue filmada por una directora. Así, este estudio se enmarca dentro de la idea Annette Kuhn "hacer visible lo invisible” (1991), es decir, estudiar no solo el papel de las mujeres como personajes de las ficciones sino como cineastas y creadoras de la industria audiovisual. La singularidad de este proyecto es aún mayor al tratarse de una readaptación, o remake, de un mediometraje rodado para Televisión Española, Vera (1971), también escrito por Salvador Maldonado y realizado por Josefina Molina. Este producto televisivo se produjo dentro del programa "Hora Once" del segundo canal de Televisión Española (TVE2), que se enmarcaba en la estrategia cultural del ente televisivo (Montero Díaz, 2018).

Esta ruptura del modelo tradicional de representación supone como indica (Owens, 2012) una forma de dar voz a los otros, en este caso a las mujeres en los cargos creativos del proyecto: dirección y guion. No es extraño que los estudios sobre Josefina Molina hayan abordado esta idea de la reivindicación feminista (Vernon, 2011; Zecchi, 2014 y 2015; y Deltell, 2015). Y que en la última década se hayan realizado tesis doctorales sobre el trabajo de la directora y su capacidad de ruptura con el modelo heteropatriarcal (Loma Muro, 2013 y Gómez Prada, 2019).

Como sostiene Barbara Zecchi, el contexto del tardofranquismo y los primeros años de la Transición no fue nada favorable para las directoras más importantes de ese momento: Josefina Molina, Cecilia Bartolomé y Pilar Miró. Y citando a la propia Molina explica: "Las palabras de Molina revelan que entre directoras se vivía una experiencia marcada inevitablemente por sentimientos de rivalidad, que, como se verá, eran más bien consecuencia de unos mecanismos de autodefensa. (...) Como consecuencia de esta falta de tradición femenina, las cineastas de su generación vivieron en un estado de 
orfandad que les causaba inseguridad y que les producía desconfianza” (Zecchi, 2014, p. 14).

Los dos proyectos audiovisuales estudiados en este artículo son adaptaciones libres de un cuento de Auguste Villiers de L'Isle-Adam: Vera. El análisis de este cuento, así como las diversas versiones que se conocen del mismo, permiten entender mejor la interpretación que Salvador Maldonado y Josefina Molina hicieron del texto francés. Por tanto, estas dos películas (una televisiva y otra cinematográfica) suponen un caso único dentro del periodo de oro del cine fantástico-terror del tardofranquismo. Su análisis y su estudio permiten entender la visión de las cineastas mujeres sobre este género.

Sin duda, uno de los aspectos centrales de este trabajo es investigar la mirada que las mujeres dan sobre la imagen del terror y del horror filmado por hombres. Es decir, Vera, un cuento cruel se puede analizar como la respuesta que propone Josefina Molina a un universo visual tan masculino. En palabras de Teresa de Lauretis (1992) lo que se intenta es revertir el código y mostrar a la mujer como sujeto, creadora e interpretadora de un género cinematográfico.

\section{2. "Vera", el cuento}

Auguste Villiers de L'Isle-Adam representaba una postura idealista y romántica en la Francia del siglo XIX. Frente al positivismo y al realismo social que se imponía en ese momento, su literatura se centraba en lo gótico, lo siniestro y en una polarización exagerada de la dualidad femeninomasculino. Su visión de la mujer se enmarcaba dentro de la misoginia decimonónica: mezcla la admiración y el miedo a lo femenino, y ello conllevaba, con frecuencia, el desprecio y el odio. Su novela de ciencia ficción La Eva Futura encarna esta mirada hacia la mujer, donde se mezclaba la saltación y el pavor (Gómez de la Serna, 1920).

Villiers había nacido en una familia nobiliaria, pero arruinada. El escritor apenas lograba sobrevivir con su trabajo y sus textos. La publicación en 1883 de sus Cuentos crueles le otorgó popularidad y un desahogo económico. Esta 
colección de relatos siniestros y misteriosos supuso su mayor éxito y por ello, años después, el autor volvió a reutilizar la fórmula con Otros cuentos crueles. Algunos de estas historias se habían publicado previamente en periódicos o semanarios, pero la mayoría eran originales e inéditos. En ellos el autor se acercaba a lo siniestro, lo gótico y lo misterioso y cada título tiene un estilo propio:

cada relato goza de entidad propia. Y esa capacidad imaginativa que comentaba es tan amplia que, siendo cada cuento, cada relato, distinto al anterior, teniendo una entidad propia, separable del conjunto, lo es también en el tono utilizado (Palacios Bernal, 1993, p. 136).

Vera se convirtió muy pronto en el cuento más conocido y valorado de estas narraciones. "Es, quizás, el cuento más celebrado de Villiers de L'Isle-Adam, y sin duda, el que muestra con mayor claridad la revelación de la materia gótica desde la sensibilidad muy próxima al fin-de-siècle" (Clúa Ginés, 2000, p. 131). La fama de este texto fue tal que en las traducciones a otras lenguas la colección se denominó: Vera y otros cuentos crueles ${ }^{1}$. El relato cuenta la historia de un joven noble parisino, el conde de Atho. En una fiesta en una embajada conoce a una misteriosa dama eslava, Vera. Ambos se enamoran y pocas semanas después se casan. La pareja se recluye en el palacio de París del noble, allí viven intensamente su deseo y su pasión. Pero la protagonista, consumida por el placer, muere mientras hace el amor con su esposo. El conde decide enterrar a su amada en la cripta de su mansión. Cierra la mazmorra y arroja la llave de la puerta a un lugar inalcanzable en el interior del sótano. Nadie podrá nunca entrar allí.

El joven se deprime. La tristeza y la melancolía le corroen y enloquecen. Así comienza a creer que su joven esposa sigue viva. Su mayordomo, asombrado y apenado, acepta su locura y lo compadece. Los dos hombres se aíslan en el caserón y viven únicamente con los recuerdos de su amada. Entonces, el joven conde sufre alucinaciones; sueña que Vera se le aparece, habla con él, le besa y ambos hacen el amor de nuevo. Estas apariciones no son compartidas por el mayordomo y por ese motivo podemos pensar que se

${ }^{1}$ Sobre el relato de "Vera" se puede escuchar en internet la conferencia pronunciada por la filóloga y traductora, Alicia Mariño en http://www.bduimp.es/view.php?idSeminario=2224. 
trata de una locura del joven conde. Así, el relato se mantiene entre lo gótico y lo realista. El lector no sabe bien si se trata de una narración de fantasmas o más bien un ensayo clínico sobre la locura ante la pérdida de un ser querido.

Villiers publicó varios finales para esta historia. En la primera versión, el joven conde moría en la cama y el espectador no podía saber si existía o no el fantasma de Vera. No obstante, en la última versión del cuento, y la que Villiers fijó como definitiva, hay una escena final diferente: el espíritu de la esposa le pide que le acompañe y, en ese momento, aparece mágicamente la llave de la cripta que el conde había hecho desaparecer. Por tanto, se trata de un fantasma existente y de un cuento de terror puro. Aunque como observó Mendoza Sánchez en otros relatos de esta Villiers, su estilo siempre se centra en la "violencia oculta” y psicológica más que en mostrar lo escabroso (Mendoza Sánchez, 2017, p. 283).

Este relato gótico se enmarca dentro de lo que Pilar Pedraza ha analizado como el "conflicto de Espectra" (Pedraza, 2004, p. 14). El hombre que se obsesiona con la mujer muerta y conserva su cadáver y, a veces, lo hace revivir; y, en otras ocasiones, es el espíritu de ella quien lo atrapa y lo devora. La autora encuentra elementos de Espectra en obras de literatura, cine y pintura. Analiza estos ejemplos desde una perspectiva muy interesante: el sueño del hombre por reencontrarse con la mujer perfecta y, en esencia, con su madre. El cuento de Vera se sitúa dentro de esta gran corriente de lo siniestro. Este mito fantástico y de terror presenta básicamente un carácter masculino: el protagonista es siempre un hombre que busca el consuelo en el cadáver de su esposa, amante o mujer deseada. Resulta inquietante que la única obra de cine de fantástico-terror filmada por una directora en España en el tardofranquismo tenga como idea central un mito tan masculino.

\section{Vera (1971) en TVE: el discurso televisivo}

La serie de televisión "Hora Once" era un proyecto de la Televisión

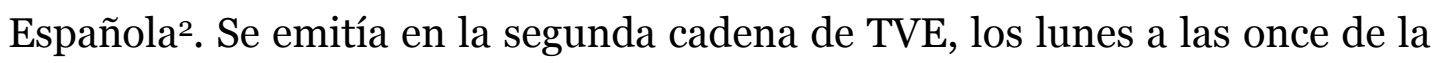

\footnotetext{
2 En algunos textos se cita este mediometraje como perteneciente a "Cuentos y leyendas". Esta serie de televisión española tampoco cuenta entre su catálogo con ninguna "Vera". Y
} 
noche, de este horario surgió su nombre. La serie comenzó su andadura en 1968 y terminó en 1974. La idea central se basaba en adaptar textos relevantes y libres de derechos de autor. Clásicos rusos, franceses, españoles e ingleses se alternaban semanalmente. La "Hora Once", compartía algunos aspectos técnicos y visuales con las famosas producciones de "Estudio Uno", aunque estas solo filmaban representaciones teatrales. Además, desde principios de la década de los setenta, tendió hacia el ciclo del horror: "en Hora Once los episodios fantásticos sólo representan una décima parte del total (...) pero su concentración a partir de 1971 demuestra un aumento del interés del género tanto en los autores como en los telespectadores" (Cruz Tienda, 2015, p. 191).

La mayoría de los capítulos de la "Hora Once" se realizó en plató, con pocos actores, con equipos pequeños y sin ningún uso de exteriores, aunque "se utilizaban tres o cuatro cámaras con una planificación de cine" (Gregori, 2009, p. 778). Todas las emisiones tenían un breve prólogo que explicaba en voice over la biografía del autor y la situación histórica en la que se escribió el texto original que se adaptaba en cada ocasión. Esta serie no era mero teatro filmado, ya que existía un proceso de adaptación real, pero tampoco un proyecto audiovisual potencialmente creativo como los de la serie "Los Libros", donde se rodaba en exteriores, interiores naturales y con varias semanas de rodaje e incluso con desplazamientos (Deltell, 2011, p. 12). Los capítulos tenían una duración de entre cuarenta y sesenta minutos. Se trata de mediometrajes que se estructuraban de forma sencilla: una larga presentación, un conflicto central desarrollado, pero no extenso y una conclusión veloz. Casi ninguno de ellos presentaba subtramas u ofrecía una multitud de personajes, y el segundo acto de las obras se diluía rápidamente sin alejarse nunca de la idea central.

Resulta difícil, sino imposible, saber el impacto o la audiencia real de la "Hora Once". En los periódicos y en la prensa del momento no se conservan críticas ni reseñas desdeñables de la serie y las escasas referencias que se encuentran se centran en la mera información de la programación televisiva.

todas las referencias de TVE así como la prensa del momento sitúan a la película como perteneciente a Hora once, diario $A B C 14$ de febrero de 1971. 
No obstante, algunos autores si indican que este capítulo "fue un éxito televisivo" (Martínez Pérez, 2016, p. 46). En cualquier caso, cada capítulo era independiente de los demás y por ese motivo surgía como un producto nuevo. Los guionistas y directores proponían a la cadena los posibles libros o cuentos a versionar (Cruz Tienda, 2015). Un aspecto clave es que fue TVE la que permitió las primeras realizaciones de las mujeres que salían de la E.O.C. Ante la imposibilidad de rodar largometrajes, las mujeres entraron en la televisión pública como el único camino para mostrar su valía (Cascajosa, 2010).

Salvador Maldonado sugirió a Josefina Molina la adaptación de Vera. La historia se ajustaba a la perfección al esquema y al formato de la "Hora Once": pocos personajes, escasos decorados y una estructura sencilla, aunque no lineal. Así, durante el año 1971 se escribió y confeccionó el primer guion de Vera, para un mediometraje de 50 minutos. Salvador Maldonado no eliminó los elementos góticos, tenebrosos y lúgubres del relato. Todo lo contrario, lo mórbido, la necrofilia y lo siniestro se desarrollan en el guion televisivo. De esta manera, el capítulo está plagado de candelabros, de velas que parpadean, de oscuridad, de ceniza, de ataúdes, de chirridos y de dolor. E, incluso, ni la guionista ni Josefina Molina omiten los aspectos más escabrosos como la sangre, los miasmas de la moribunda, el ataúd abierto y el cadáver de Vera en descomposición - aunque no se muestra directamente, pero se referencia con el protagonista asqueado que debe taparse la nariz-.

Sin embargo, el relato de Salvador Maldonado presenta una diferencia esencial. La trama de la película ya no se centra en el fantasma de Vera (interpretado por Enriqueta Carballeira) que busca y desea arrastrar al joven conde, sino en la relación de este con su mayordomo. En el capítulo Salvador Maldonado y Josefina Molina presentan a un conde enloquecido (interpretado por José Carlos Plaza) que consigue que el mayordomo, Raymond (Fabio León), acepte y compadezca su desdicha. Sin embargo, a medida que la historia avanza Raymond enloquece y él mismo termina creyendo la existencia de Vera. El conde se sorprende al ver que el mayordomo prepara el fuego en la habitación vacía y coloca la ropa de cama de la condesa. 
La escena clave de este producto televisivo es la visita del sacerdote, cuarto personaje de la obra. El clérigo -interpretado por José Vivó- despierta del ensueño al conde. Tras escuchar al cura, el joven noble acepta su enfermedad y sigue el consejo del religioso, descorre las ventanas y descubre que en el exterior de la casa es primavera y que debe vivir. Es aquí donde se produce el cambio entre el relato de Villiers y el mediometraje: el mayordomo, al comprender que su amo no cree en la Vera viva, decide encerrarle en la cripta de la casa y matarlo. A diferencia del relato, en el que el fantasma de Vera deja la llave encima de la cama, en este caso el espíritu de ella le da al mayordomo la llave para que éste la deposite en la cama. Roger acude a la cripta y allí es encerrado por Raymond, que sonríe enloquecido.

La relación de Roger y Raymond recuerda poderosamente a la de Don Quijote y Sancho. Cuando el hidalgo está loco el labrador mantiene la cordura, cuando Don Quijote sana, Sancho enloquece. Algo similar ocurre en la película. La locura se desplaza de uno a otro dentro de ese caserón lúgubre. Se trata de mostrar cómo la enfermedad mental, la psicosis, llega a contagiarse. Sin embargo, esto no se debe entender como una explicación lógica del relato. No se trata de un estudio científico sobre la cordura o la locura, ya que el objeto central del relato, aquel que lo hace realmente fantástico, es la llave de la cripta que aparece también, como en el relato, misteriosamente. Vera le da al mayordomo la llave para que este arguya el siniestro plan.

Así, las dos creadoras han construido un universo tenebroso propio de la novela gótica inglesa y del simbolismo francés, pero a la vez poético. La sangre, los esputos de la joven se muestran sin tapujos, pero siempre con sutileza. Toda la narración es pretendidamente intelectual y hermosa. Los diálogos son literarios reforzando este carácter poético de la narración. Además, las autoras incluyen un famoso texto de Baudelaire que se repite incesantemente durante el relato: "Tendremos un lecho de suaves olores. Divanes profundos como sepulturas y flores extrañas para nosotros abiertas bajo albas más puras. Su calor postrero usando porfía, serán dos antorchas nuestros corazones, que reflejarán sus dobles espejos gemelos en tu alma y la mía, hecha de azul y rosa místico una tarde cambiaremos ese relámpago que 
arde cargado adioses cual largo sollozo. Y después un ángel abriendo las puertas vendrá a reanimar fiel y jubiloso los espejos turbios y las llamas muertas"3.

El universo gótico y simbolismo se refuerza poderosamente con la puesta en escena. Aún con los escasos recursos de producción que ofrecía la "Hora Once", Josefina Molina presenta una obra compleja: por un lado, casi la mitad del mediometraje carece de sonido directo y se acompaña de música y de voz en off -la repetición del poema del poeta francés principalmente-; por otro lado, la autora no renuncia a los elementos clásicos del cine de terror -las sombras alargadas, los espacios cerrados, los personajes y las interpretaciones exageradas-. Todo ello hace de la película para televisión una propuesta arriesgada y original.

Este mediometraje no se aleja de los cánones estéticos y expresivos del cine terror, pero sí se distancia de la temática dominante. El fantasma, el miedo o la violencia son en los relatos clásicos del terror el centro de la narración. En Vera el tema fundamental es el amor: el deseo hacia una muerta. Curiosamente, el sujeto del amor, la joven protagonista, no tiene casi texto, carece de diálogos directos y lo poco que le oímos es en voz en off. La protagonista femenina queda intencionalmente muy desdibujada.

En la novela de Villiers no se habla de más mujeres que de Vera. Sin embargo, intuimos que hay otras en la boda, en el entierro, en la fiesta donde se conocen y entre los sirvientes de la mansión. En el mediometraje televisivo, las mujeres han desaparecido completamente, en la boda y en la fiesta hay figurantes mujeres, pero no hay ningún personaje femenino con texto salvo la propia Vera. Así, el objeto amado, Vera, no solo es una mujer, sino la mujer en sí misma. Esta insólita ausencia nos ayuda a entender la locura del Conde, pero también la de Raymond, pues ambos se entregan no a un fantasma cualquiera, sino al fantasma de la única mujer.

Enriqueta Carballeira no representaba el ideal de belleza rusa que se describe en el relato de Villiers, en un esquema completamente heteronormativo.

3 Traducción libre del poema de Baudelaire "La muerte de los amantes", Suplemento CXXI a las Flores del mal. 
Mientras el escritor habla de una mujer con rasgos rubios y eslavos, Enriqueta Carballeira resulta una mujer mediterránea por antonomasia, esta ruptura con el modelo heteronormativo será repetido posteriormente en Lola se va a los puertos (Josefina Molina, 1983), como indica Barbara Zecchi (2015, p. 60). La actriz es una de las intérpretes femeninas que más colaboraciones hizo en la "Hora Once". El retrato y el protagonismo, que se da a la única mujer de en el mediometraje, resultan interesantes, ya que se trata de una víctima y de una vampiresa a la vez. Curiosamente poco se diferencia de la visión icónica del género ideado por los hombres. Primero es una mujer deseada y seducida hasta la voluptuosidad extrema que le provoca la muerte. Al igual que en el vampirismo, su fallecimiento se muestra con chorros de sangre que salen de su boca. Pero una vez muerta, la mujer se transforma en una vampiresa dispuesta a arrastrar a su amado, encajando en la idea de mujer fatal analizada por Pedraza (2004).

La obra se emitió el 15 de febrero de 1971 en el segundo canal de Televisión Española. No hemos encontrado ninguna otra emisión registrada en archivos o difundida por la prensa, y no se vendió a ninguna cadena extranjera ni tampoco se hicieron críticas ni referencias a ella más allá de indicar su programación. La historia parecía condenada al olvido, sin embargo, dos años después la directora decide adaptar de nuevo el relato del escritor francés.

\section{Vera, un cuento cruel (1973). Una directora española en el cine fanta-terror español}

En 1972 Gabriel Moralejo y José Sámano, que colaboraba como director de producción en la empresa Etnos Films4, ofreció a Josefina Molina la posibilidad de filmar su primer largometraje. Hasta ese momento la directora

\footnotetext{
4 Etnos Films es una productora menor y como ocurre habitualmente en el cine español resulta difícil conseguir información sobre ella. Gabriel Moralejo Hernández es el que registra el nombre de Etnos Films. Existen dos películas producidas por esta empresa: Vera, un cuento cruel (1973) y La historia y vida extraterrestre (1976). Esta última dirigida por Juan García Atienza y Álvaro Saavedra. Los dos largometrajes surgen de forma independiente, pero colocan a Etnos como una productora dedicada en exclusiva a la temática fantástica y paranormal.
} 
había grabado para Televisión Española proyectos para la "Hora Once" pero también había filmado teatros para "Estudio Uno" y "Pequeño Estudio". No se trataba de una creadora inexperta ya que, a parte de su etapa en televisión, habría que añadir sus tres prácticas regladas en la Escuela Oficial de Cinematografía (Deltell, 2015). En 1967 había sido la primera egresada de la institución educativa en la especialidad de Dirección Cinematográfica, hecho que fue publicado y celebrado como un acontecimiento incluso en la prensa nacional (Blasco, 1969).

El proyecto de Vera, se encontraba parado pues tres cineastas habían rechazado o reusado dirigirlo: Mario Camus, Pedro Olea y Miguel Picazo (Gregori, 2009, p. 779). Sin embargo, José Sámano creyó que se encontraba ante un trabajo atractivo y con posibilidades económicas (Molina, 2000). Productor y directora acordaron reescribir un texto inicial presentado por los guionistas Salvador Maldonado y Juan Tébar como propuesta de adaptación. La elección de Juan Tébar no es casual, este escritor había destacado en el cine fantástico y terror español. Una de sus ideas inspiró uno de los largometrajes más importantes del género: La residencia (Narciso Sánchez Serrador, 1969)5. En realidad, la nueva propuesta se trataba de una remake o reelaboración del capítulo de "Hora Once", por ello, la trama central no sería ya la muerte y resurrección del espíritu de la Vera, sino más bien la relación entre el conde y el mayordomo como había sido en el proyecto televisivo. Al igual que en el mediometraje, el sirviente (que ahora se llamará Roger) terminará encerrando y matando al noble.

No obstante, la primera versión de los guionistas no gustó al productor y a la directora. Estos no se sintieron conformes y decidieron que la realizadora interviniese en la escritura. En la censura española se conserva una copia del guion, firmado por Salvador Maldonado, Juan Tébar y Josefina Molina. Este texto es básicamente el largometraje final ${ }^{6}$. Sin embargo, esta versión no convenció a los dos guionistas que consideraban que se distanciaba tanto de

\footnotetext{
5 Aunque el guion del largometraje lo firmó solo el director, éste reconocía la importancia del relato de Juan Tébar, en el cual se inspiró para realizar la obra.

${ }^{6}$ Existen dos guiones inéditos de Vera, un cuento cruel. Versión Primera: G-895; Versión Segunda: G-1491. Entre ambas hay pocas diferencias y las dos están firmadas por la directora y los dos guionistas.
} 
sus ideas que pidieron no firmar el texto (Gregori, 2009, p. 779). El productor y la directora aceptaron y terminaron firmando el guion $\mathrm{y}$ excluyeron a los dos guionistas previos. José Luis Martínez Montalbán recoge en un artículo que tanto Lola Salvador como Juan Tébar se sintieron heridos por esta decisión y, sobre todo, por no haber logrado un consenso (Martínez Montalbán, 2006, p.12).

El texto fue aprobado sin grandes dificultades por la censura española que ya había aceptado otros proyectos de cine fantástico-terror con asiduidad. A principios de los años setenta la junta de censura había centrado su empeño controlador, sobre todo, en las cuestiones políticas y otorgaba cierta libertad en lo sexual, lo erótico y lo fantástico (Gubern y Font, 1975, p. 151-152). Además, en el caso de Vera, un cuento cruel presentaba un atenuante - a posibles críticas- ya que se añadía la aureola de ser un proyecto estético e intelectual basado en un autor conservador y clásico.

El largometraje es una nueva lectura de la obra de Vera. Al igual que el mediometraje comienza con la boda, pero en este caso la situación es distinta: Vera es francesa -y se apellida Villiers en honor al autor galo- y el conde es un español. Ambos se casan en Francia y, después, se instalan en el caserón de la familia del noble, en el norte de España. Junto a ellos viaja el mayordomo de ella (Roger). En el caserón la pareja vive feliz, pero como en el texto, la joven muere en pleno acto sexual. Vera es enterrada en la cripta de la casa. El conde, al igual que en las otras versiones, hace desaparecer la llave de la cripta.

El protagonista decide aislarse del mundo y encerrarse en su mansión, pero a diferencia del cuento y del mediometraje en el largometraje no será posible el encierro misántropo, ya que un antiguo amor, María (interpretado por Julieta Serrano), se esforzará en averiguar los motivos del aislamiento. El joven conde es visitado insistentemente por la mujer y al final termina por aceptar sus cuitas e, incluso, a cabalgar con ella por los prados cercanos.

La idea, que se desprendía en el mediometraje, de que Vera era la única mujer existente desaparece completamente en esta película. Ahora, Vera es la dama ideal frente al personaje de María que es imperfecta pero real. 
Curiosamente esta dualidad nos aporta más información: Vera, el cadáver que se descompone en la cripta, es el ideal -toda ella perfecta, sofisticada y elegante-. Sin embargo, María es la fémina real, viva y que se opone a aceptar los engaños y las locuras del conde. El hombre debe luchar entre la dama ideal -inexistente y muerta - o la mujer imperfecta pero viva. Como en todo relato gótico el protagonista se decanta por lo ideal, es decir: por el concepto de la madre y a ella acude fatalmente.

El personaje de Roger (interpretado por Fernando Fernán Gómez7) es mucho más complejo en la nueva versión. Así cae en la locura y acepta que Vera está viva. Según nos cuenta el propio protagonista ha sido el siervo de ella desde su infancia, ha vivido con ella y la ha acompañado siempre y, por eso, se siente en la obligación de protegerla aún fallecida. Por este motivo, vive los encuentros del conde con su antiguo amor, María, como infidelidades a su señora. Cuando el conde recobra la cordura y comprende que Vera realmente está muerta, el mayordomo se vuelve loco. Roger organiza toda una trama para enloquecer al señor. Se trata del mismo proceso que sucede en la película Luz de Gas (Gaslight, 1944) de George Cukor. Roger sibilinamente convence a María, y con su ayuda, fingen ruidos, pasos y hasta apariciones de Vera. El mayordomo encierra en la cripta al conde donde muere, envenena a María, y huye con el cadáver de Vera a Francia.

El relato pierde en fantasía, resulta difícil saber si todas las apariciones, fantasmas e ilusiones que se ven en la película son reales, imaginarias o construcciones tramposas y arteras del mayordomo para hacer creer al conde -y al espectador- que Vera sigue viva. Sin embargo, hay dos acontecimientos que mantienen la película dentro del terror: el primero es puramente fantasioso e irreal -aunque completamente verosímil dentro del género-, la llave que el conde ha tirado dentro de la cripta aparece en la mano del mayordomo sin explicación alguna; el segundo no es irreal, pero resulta igualmente terrorífico, la escena final de la película cuando el mayordomo se marcha de viaje con el cadáver de Vera.

7 Desde su estreno en el festival de San Sebastián, todas las críticas y reseñas periodísticas destacan el trabajo y la interpretación de Fernando Fernán Gómez que transforma al mayordomo en una creación viva y compleja. 
En la última escena del filme, Roger tranquilamente recoge el equipaje y lo carga en un carruaje, sube en él y lo conduce, y en el interior del vehículo viaja el cadáver embalsamado de Vera. En la tradición cultural y literaria española hay otro caso de amante que pasea el cadáver de su amada. Como recoge Pilar Pedraza, Ramón J. Sender en La muñeca en la vitrina: bajo el signo de Virgo (Sender, 1980, p. 143) había relatado el caso verídico de los doctores Velasco y Muñoz, padre y novio de una joven que falleció. Los dos hombres desesperados por la muerte de la joven, la embalsaman y viven con el cadáver como si estuviera vivo, incluso: "Las malas lenguas dijeron que padre y novio la sacaban a pasear en coche e incluso la sentaban en la mesa" (Pedraza, 2004, p. 171).

Lo mismo ocurre en el mediometraje, la Vera de la película es un personaje poco o nada atractivo. Se trata de una mujer bella y, supuestamente, alegre y jovial; pero el espectador no descubre nada real de ella. Solo sabemos que su entrega al conde le llevó a la muerte en medio de un orgasmo, no la escuchamos ni sabemos cómo se enamoraron ni podemos participar de sus encuentros previos a la muerte. Lo que nos queda es un fantasma que se pasea por el caserón.

Tanto la guionista como la directora repiten el icónico misógino de las películas españolas de terror de estos años. La mujer es víctima y verdugo: así ocurre en muchas de ellas, la ya citada La residencia, pero también en $L a$ corrupción de Chris Miller (Juan Antonio Bardem, 1973) o en Trauma (León Klimovsky, 1978). El esquema es muy sencillo, una dama joven y, más o menos, inocente es seducida por el mal, la locura o la enfermedad y una vez que ha caído en la desgracia, ella se transforma en el peor de los monstruos imaginarios.

La actriz Mel Humphreys ${ }^{8}$ se acerca a la belleza que se menciona en el relato de Villiers y se aleja de la visión mediterránea que se ofrecía en el

\footnotetext{
8 Mel Humphrey es el pseudónimo de una actriz, persona que nos ha sido imposible identificar. Curiosamente ni la prensa del momento ni los críticos mencionan el verdadero nombre de dicha intérprete. No se conoce ninguna otra película en la que figure dicha actriz, al menos con este pseudónimo. Aunque existe un joven director norteamericano llamado Mel Humphrey, éste no mantiene relación alguna con tan misteriosa actriz. En entrevista a
} 
mediometraje. Sin embargo, como en la mayoría de las películas del género pronto se convierte en un mero objeto de contemplación. Al igual que las otras víctimas del ciclo fílmico, su cuerpo es usado como objeto de erotismo y de tortura. La joven desnuda repite una y otra vez los gestos y las posturas que le llevarán al orgasmo mortal que terminará con su vida. Los desnudos se justifican con el aspecto esteticista y pretendidamente intelectual. $\mathrm{Y}$, al igual que en el mediometraje, los protagonistas repiten, una y otra vez, un texto de Charles Baudelaire, en este caso un fragmento de "La metamorfosis del vampiro": "Yo tengo los labios húmedos y conozco la ciencia de perder la razón en el fondo del lecho. Seco todas las lágrimas con mis pechos triunfantes y hasta la vejez se ríe como un niño. Soy el sol y las estrellas, para aquel que ve mi cuerpo sin velos. iSoy sabia en besos y soy amada!”.

En el mediometraje televisivo, Josefina Molina había usado algunos efectos propios de la estética del género de terror. En este largometraje, la directora también reutiliza estas herramientas, pero casi todas quedan diluidas en la propuesta de embellecimiento del proyecto. El continuo esteticismo aleja la obra del género fantástico y terror. Así, el fantasma, los candelabros, las sombras, la cripta e incluso los esputos, los miasmas y el cadáver aparecen como hermosos y bellos.

Toda esta "belleza necrófila" se acentúa en una escena fundamental del relato: Un viejo conocido (interpretado por Alfredo Mayo) y sus dos hijos adolescentes (interpretados por los hermanos Bosé) 9 visitan al conde. El joven viudo les habla de Vera como una mujer viva y ellos se escandalizan. El conde en un arrebato de pasión conduce a sus huéspedes a la cripta. Mientras ellos se horrorizan por lo tétrico y nauseabundo del lugar, él se queda obnubilado por el sublime recuerdo de su desdichada amada.

El lirismo y el aspecto poético del largometraje se enfatiza gracias al trabajo del director de fotografía José Luis Alcaine, al que Josefina Molina conocía de la Escuela Oficial de Cinematografía (E.O.C.), aunque no habían

los autores de este artículo, Josefina Molina no reconocía que tampoco recordaba el nombre de la intérprete.

9 Uno de los motivos por los cuales Vera, un cuento cruel se encuentra citada y reseñada en internet y archivos periodísticos se basa precisamente en que es el debut de los hermanos Bosé (Lucía y Miguel). 
compartido prácticas o enseñanzas ${ }^{10}$. La luz de la película es tenue, amarillenta y cuidada. En muchos aspectos la iluminación recuerda a los tonos miel que Luis Cuadrado había logrado en El espíritu de la colmena (1973). La comparación no resulta casual, ya que ambas se estrenaron en el Festival de San Sebastián el mismo año. Pero mientras que la propuesta de Víctor Erice se ajusta perfectamente al lirismo de su guion, no ocurre lo mismo en Vera, un cuento cruel; aquí el esteticismo resulta extraño y, a veces, excesivo.

Sin embargo, el esteticismo que propone Molina le sirve para alejarse de la hipersexualización del género fantástico durante el franquismo. Como observa García Fernández y Cordero Domínguez, así las películas de terror contemporáneas a Vera, un cuento cruel son claramente sexistas y los desnudos (femeninos) y la violencia excesiva parece no ir acorde con la narración (García Fernández \& Cordero Domínguez, 2017, pp. 60-61).

Esta forma de reconducir la violencia que ofrece Josefina Molina en Vera, un cuento cruel resulta un ejemplo paradigmático de la propuesta de Linda Willlians entre el cine de terror y el melodrama (Williams, 1991, p. 9.). Mientras que el primero se centra en aspectos físicos (violentos sobre el cuerpo) el segundo enfatiza aspectos psicológicos (violencia de las emociones - como la muerte de un ser querido). El cine de terror, indica Williams, oculta una obsesión por el sadomasoquismo mientras que el melodrama parece esconder una tendencia masoquista. En el cine de terror, clásico, escribe la autora estadounidense, todo llega demasiado pronto ("too early!") mientras en el melodrama todo parece sentenciado y no volverá a ocurrir ("too late!"). La propuesta de la directora en su film parece reconducir esa tendencia sadomasoquista propia del cine de terror y reconducirla hacia una visión más estética y melodramática.

Otro aspecto clave en el largometraje de Josefina Molina. Como sostiene Kuhn, el feminismo en el cine no solo es el retrato de la mujer en las películas sino también el papel de las cineastas y las cuotas de poder que estas

${ }^{10}$ José Luis Alcaide estudió en la E.O.C. desde 1962 a 1964 en la rama de fotografía, mientras Josefina Molina lo hizo desde 1964 a 1968. 
alcanzan. El impacto que supuso que una directora mujer hiciese una obra de terror fue brutal, así toda la prensa especializada refleja el hecho como una novedad insólita, o en palabras de Kuhn como una revelación de lo invisible. La elogiosa crítica de López Sancho (1974) en $A B C$ enfatiza el hecho de que se trata de una directora. Algo que repiten Galán (1974) en Triunfo; en Diario Ya Martialay (1974); y en Informaciones (Rubio, 1974) y (Sánchez, 1974). Como sostiene Begoña Siles en su trabajo sobre Pilar Miró y el cine filmado por mujeres en España, "nombrar para recordar. (...) puede parecer superficial, no lo es tanto si tenemos en cuenta el larguísimo silencio que ha existido en torno al trabajo de la mujer en el cine” (Siles, 2006, p. 284.).

\section{Conclusiones: un relato dos miradas de una mujer a un género cinematográfico}

Vera y Vera, un cuento cruel son dos productos audiovisuales extraordinariamente originales y relevantes. Se trata de las únicas aportaciones realizadas por guionistas mujeres y por una directora al cine fantástico y de terror español en el período de esplendor del mismo. Su análisis nos presenta algunas ideas destacadas y valiosas, ya que son ejemplos únicos dentro de un género dirigido y escrito por hombres en España durante el franquismo.

La primera diferencia es que Josefina Molina utiliza estrategias narrativas para comprender la locura y para dar verosimilitud al relato. Su intención no es transformar sus obras en tratados científicos sobre enfermedades mentales, pero dan más explicaciones y buscan más coherencia que la mayoría de los directores hombres. Lo terrorífico en estas obras es más lo propiamente humano que lo fantástico. Tanto Lola Salvador Maldonado como Josefina Molina se separan del discurso tradicional del terror y de lo fantasmal propio del cine de horror español, para acercarse más a un horror psicológico. En esta película lo terrorífico no son las apariciones, sino la locura y la psique del hombre, como amante, marido y compañero.

Aunque en ninguna de las dos obras se disimula lo violento y lo tenebroso, sí existe un proceso continuo de embellecimiento de la obra. La estética es 
fundamental en los dos productos audiovisuales. Especialmente el largometraje Vera, un cuento cruel es un ejercicio esteticista, donde Josefina Molina se esfuerza por crear un cine fantástico elegante y sutil, muy alejado de los modelos clásicos de representación del cine de terror español de esos años dirigido por hombres.

Curiosamente es en el retrato de la mujer donde menos se diferencia o se aleja de los códigos del género de terror. Al igual que ocurre en la mayoría de las obras, estas dos cineastas presentan a sus "Veras" como víctimas inocentes y después asesinas crueles: víctimas de la sexualidad y, tras la desgracia, se convierten vengativas y sanguinarias como vampiresas. La sexualidad y el placer femenino se muestran como enfermizos y mortales. La satisfacción y el orgasmo conllevan la muerte de la protagonista, la cual una vez muerta reclama la vida de su amado para seguir satisfaciendo su deseo sexual.

Por último, el protagonista masculino aparece como víctima del misterio y de la locura. En ambos filmes el conde cae en una profundísima depresión y enloquece. La violencia física (propia del cine del terror) deviene en una violencia psicológica (más propia del cine melodramático). Aún más inquietante es el personaje del mayordomo que, primero compasivo y luego neurótico, considera que Vera sigue viva y debe cuidar y proteger el cadáver.

Vera y Vera, un cuento cruel nos sirven para estudiar y entender los mitos y los esquemas del cine fantástico y de terror español desde la perspectiva de dos creadoras mujeres: Lola Salvador Maldonado y Josefina Molina. Y, sobre todo, se presentan como únicos ejemplos la idea del pensamiento de Kuhn: "hacer visible lo invisible”. Por primera vez en España, una mujer dirigía una película en un género marcadamente masculino.

\section{Referencias bibliográficas}

ABC. (1974). Vera, un cuento cruel. $A B C, 11$ de julio de 1974.

ABC. (1974). Reseña de parrilla televisiva. $A B C, 14$ de febrero de 1971.

Baudelaire, C. (2010). Fleurs du mal. Flores del mal. Edición bilingüe, Sevilla, España: Renacimiento. 
Blasco, J. J. (1969). La primera mujer española diplomada en Dirección Cinematográfica. Josefina Molina Reig. Diario Alcázar, 28 de octubre de 1969,

Cascajosa, C. (2010). Mujeres creadoras de ficción televisiva en España. En: P. Sangro, Pedro \& J. P. Plaza (Ed). La representación de las mujeres en el cine y la televisión contemporáneos. Barcelona: Laertes, p. 177197.

Cordero Domínguez, A. (2015). Aportaciones de Narciso Ibáñez Serrador al cine fantástico-terrorífico español.[Tesis] Madrid, España: Universidad Complutense de Madrid.

Clúa Ginés, I. (2000). Los secretos de las damas muertas: dos reelaboraciones de lo fantástico en la obra de Emilia Pardo Bazán. Cuadernos de Investigación Filológica, Vol. 26. Pp. 125-135. DOI: https://doi.org/10.18172/cif.2223

Deltell, L. (2011). José Jara: Un apocalíptico en el cine, un refugiado en la universidad, Área Abierta, Núm. 30. DOI: https://doi.org/10.5209/rev_ARAB.2011.n30.37837

Deltell, L. (2015). La mujer como sujeto. Josefina Molina en la Escuela Oficial de Cine. Signa, Revista de la Asociación de Semiótica, Volumen 24. Pp. 293-306.

Duramo (1975). Vera, un cuento cruel, de Josefina Molina, Lanza, 18 de octubre de 1975.

Galán, D. (1974). Vera, un cuento cruel de Josefina Molina, Triunfo, Año XXIX, n. 615, 13 de junio de 1974.

García Fernández, E. C. (Editor) (2010). Historia del cine. Madrid: Fragua.

García Fernández, E. C. \& Cordero Domínguez, A. (2017). Sangre y sexo en el cine de terror español. Fotocinema. Revista científica de cine y fotografia, $\quad \mathrm{n}^{\mathrm{0}} \quad 15, \quad \mathrm{pp} . \quad 37-62$. https://doi.org/10.24310/Fotocinema.2017.voi15.3496

Gómez de la Serna. R. (1920). Prólogo. En A. Villiers De L’Isle-Adam. Eva futura y nuevos cuentos crueles. Madrid, España: Biblioteca Nueva.

Gómez Prada, H. C. (2019). La obra cinematográfica de Josefina Molina en la historiografía del cine español: un análisis audiovisual. [Tesis] Madrid. Universidad Complutense de Madrid.

Gregori, A. (2009). El cine español según sus directores. Madrid: Cátedra.

Gubern, R. \& Font, D. (1975). Un cine para el cadalso. Barcelona: Euros.

Kuhn, A. (1991). Cine de mujeres: Feminismo y cine. Madrid: Cátedra.

Lauretis, T. de (1992). Alicia ya no: feminismo, semiótica, cine. Madrid: Cátedra.

Lesage, J. (1974). Feminist Film Critcism: Theory and Pratice. Women and Film, 5, 12-20.

Llinás, F. (ed.) (1999). 50 años de la Escuela Oficial de Cine/ Instituto de 
Investigaciones y Experiencias Cinematográficas. Madrid: Filmoteca Española.

Loma Muro, E. (2013) Las imágenes de Josefina Molina: de la escritura literaria a la audiovisual. [Tesis] Madrid: Universidad Carlos III de Madrid. Servicio de Publicaciones de la Universidad de Córdoba, http://helvia.uco.es/xmlui/handle/10396/10756 [20/07/2013].

López Sancho, L. (1974). Precioso y ejemplar filme español: Vera, un cuento cruel, $A B C, 10$ de julio de 1974 .

Martialay, F. (1974). Vera, un cuento cruel, Diario Ya, 10 de julio de 1974.

Martínez Montalbán, J. L. (2006). Lola Salvador Maldonado, Arbor, Vol 182, N. 720.

Martínez Pérez, N. (2016). Mujeres creadoras de ficción televisiva durante la transición española (1974-1981). [Tesis] Madrid: Universidad Carlos III de Madrid.

Medina, E. (2000). El cine negro y policiaco en el cine español de los cincuenta. Barcelona, España: Laertes.

Mendoza Sánchez, A. (2017). De la literatura fantástica al cine surrealista checo: poética de la transgresión en Kyvadlo, jáma a naděje de Jan Švankmajer. Fotocinema. Revista científica de cine y fotografía, $\mathrm{n}^{\mathrm{0}}{ }_{14}$, pp. 275-293. https://doi.org/10.24310/Fotocinema.2017.voi14.3602

Molina Reig, J. (2000). Sentada en un rincón. Valladolid: SEMINCI.

Montero Díaz, J. (director) (2018). Una televisión con dos cadenas. La programación en España (1956-199o). Madrid: Cátedra.

Muñoz Giner, A. (2011) "El erotismo en el cine de terror español”, Trabajo de investigación [Tesisna] Madrid: Departamento Cavp 1.

Mulvey, L. (1999). Visual Pleasure and Narrative Cinema. Film Theory and Criticism: Introductory Readings. Eds. Leo Braudy and Marshall Cohen. New York: Oxford UP, 833-44.

Palacios Bernal, C. (1993). La escritura de los Contes cruels de Villiers de 'Isle-Adam. Revista de Filología Francesa, 4. Editorial Complutense, Madrid.

Pedraza, P. (2004). Espectra. Descenso a las criptas de la literatura y el cine. Madrid: Valdemar.

Pedraza, P. (1991). La bella, Esfinge, Medusa, Pantera... Enigma y pesadilla. Barcelona: Tusquets Editores.

Owens, C. (2002). El discurso de los otros: las feministas y el posmodernismo. En La posmodernidad, H. Foster (ed.), (pp. 43-47). Barcelona: Kairós.

Riambau, E. \& Torreiro, C. (1998). Guionistas en el cine español. Quimeras, picarescas y pluriempleo. Madrid: Cátedra / Filmoteca Española.

Rubio, M. (1974). Vera, un cuento cruel, de J. Molina, Informaciones, 7 de julio de 1974 . 
Sánchez, A. (1974). Vera, un cuento cruel, Informaciones, 9 de julio de 1974.

Sender, R. J. (1980). La muñeca en la vitrina: bajo el signo de Virgo. Barcelona: Destino,

Siles, B. (2006). La mirada de la mujer y la mujer mirada (En torno a Pilar Miró). Bilbao: Universidad País Vasco.

Vernon, K. (2011). Cine de mujeres en la Transición. La trilogía 'feminista' de Cecilia Bartolomé, Pilar Miró y Josefina Molina. En: Palacio, Manuel ed. El cine y la Transición política en España (1975-1982), (pp. 145158). Madrid: Biblioteca Nueva.

Villiers de L'Isle-Adam, A. (1920). Eva futura y nuevos cuentos crueles. Prólogo de Ramón Gómez de la Serna. Madrid: Biblioteca Nueva.

Willians, L. (1991). "Film Bodies: Gender, Genre and Excess". Film Quarterly, Vol. 44, Núm. 4 (Summer, 1991), pp. 2-13.

Zecchi, B. (2014): Desenfocadas: cineastas españolas y discursos de género. Barcelona: Icaria.

Zecchi, B. (2015). La españolada al femminile. Rassegna iberistica, Vol. 38, Núm. 103, Giugno. pp. 43-64.

Webgrafía

Conferencia de la investigadora y filóloga Alicia Mariño sobre el relato "Vera": http://www.bduimp.es/view.php?idSeminario=2224

\section{Documentación Filmoteca Española}

Archivo Etnos Films -ficha de la película Vera, un cuento cruel (documentación para prensas española e italiana).

Guion inédito: Vera, un cuento cruel. Versión Primera: G-895; Versión Segunda: G-1491.

\section{Documentación Archivo General de la Administración}

Expediente administrativo: 36/05648.

Censura previa de guion y censura de la película.

\section{Documentación no editada o venial depositada en la Biblioteca} Nacional

Guion inédito: "Vera, un cuento cruel”.

\section{Documentación no editada de RTVE}

Mediometraje: Vera (1971). Código: DBGAF274 y cinta 4Q 3867. Emisión 15 de febrero de 1971.

\section{Filmografía}

Molina, J. Vera (1971). España: RTVE.

Molina, J. Vera, un cuento cruel (1973). España: Productora Etnos. 